\title{
Absorption and safety of serum-derived bovine immunoglobulin/protein isolate in healthy adults
}

This article was published in the following Dove Press journal:

Clinical and Experimental Gastroenterology

5 December 2016

Number of times this article has been viewed

\author{
Audrey L Shaw' \\ David W Mathews' \\ John E Hinkle 2 \\ Bryon W Petschow \\ Eric MWeaver ${ }^{3}$ \\ Christopher J Detzel' \\ Gerald L Klein ${ }^{4}$ \\ Timothy P Bradshaw' \\ 'Clinical Development, Entera Health, \\ Inc., ${ }^{2}$ Life Sciences Consulting and \\ Analytics, EarlyPhase Sciences, Inc., \\ Cary, ${ }^{3}$ Executive Management, Prairie \\ Pharms, LLC, Nora Springs, ${ }^{4}$ Executive \\ Management, MedSurgPI, LLC, Raleigh, \\ NC, USA
}

Correspondence: Audrey L Shaw Clinical Development, Entera Health, Inc., 2000 Regency Parkway, Suite 255, Cary, NC 275 I8, USA

$\mathrm{Tel}+1919$ 97| 8000

Email audrey.shaw@enterahealth.com
Purpose: Previous studies have shown that oral administration of bovine immunoglobulin protein preparations is safe and provides nutritional and intestinal health benefits. The purpose of this study was to evaluate the plasma amino acid response following a single dose of serumderived bovine immunoglobulin/protein isolate (SBI) and whether bovine immunoglobulin $\mathrm{G}(\mathrm{IgG})$ is present in stool or in blood following multiple doses of SBI in healthy volunteers.

Methods: A total of 42 healthy adults were administered a single dose of placebo or SBI at one of three doses $(5 \mathrm{~g}, 10 \mathrm{~g}$, or $20 \mathrm{~g})$ in blinded fashion and then continued on SBI $(2.5 \mathrm{~g}, 5 \mathrm{~g}$, or $10 \mathrm{~g}$ ) twice daily (BID) for an additional 2 weeks. Serial blood samples were collected for amino acid analysis following a single dose of placebo or SBI. Stool and blood samples were collected to assess bovine IgG levels.

Results: The area under the curve from time 0 minute to 180 minutes for essential and total amino acids as well as tryptophan increased following ingestion of $5 \mathrm{~g}, 10 \mathrm{~g}$, or $20 \mathrm{~g}$ of SBI, with a significant difference between placebo and all doses of SBI $(p<0.05)$ for essential amino acids and tryptophan but only the $10 \mathrm{~g}$ and $20 \mathrm{~g}$ doses for total amino acids. Bovine $\operatorname{IgG}$ was detected in the stool following multiple doses of SBI. No quantifiable levels of bovine IgG were determined in plasma samples 90 minutes following administration of a single dose or multiple doses of SBI.

Conclusion: Oral administration of SBI leads to increases in plasma essential amino acids during transit through the gastrointestinal tract and is safe at levels as high as $20 \mathrm{~g} /$ day.

Keywords: bovine immunoglobulin, intestinal absorption, plasma amino acids

\section{Background}

The passive immunity transferred to newborns in a number of animal species through ingestion of mother's colostrum or milk demonstrates the important biological role played by oral immunoglobulins. ${ }^{1}$ Bovine serum is similarly rich in antibodies and contains up to $25 \mathrm{mg}$ of immunoglobulins per milliliter - the majority of which is in the form of immunoglobulin G (IgG)., Numerous studies in young animals have demonstrated that oral administration of bovine plasma- or serum-derived protein concentrates, which contain high levels of these immunoglobulins, leads to improvements in appetite, weight gain, intestinal growth, and gut barrier function. ${ }^{3,4}$ More recently, there has been increasing interest in the use of such immunoglobulin-containing protein isolates from bovine plasma or serum in human beings at risk for certain intestinal disorders or to help manage chronic conditions affecting the gastrointestinal (GI) tract. 
The beneficial effects of orally administered immunoglobulins depend upon the passage of these proteins through the stomach and into the lumen of the lower GI tract. During this transit, it is presumed that these proteins are resistant to degradation by gastric acid, pepsin, and pancreatic and small intestinal digestion enzymes as well as proteolytic enzymes released by the colonic microflora. Results from a number of studies in human beings indicate that significant amounts of orally administered immunoglobulins retain antigen-neutralizing activity along the GI tract, based on the recovery of intact and immunologically active $\operatorname{IgG}$ in ileal contents and feces..$^{5-8}$

Serum-derived bovine immunoglobulin/protein isolate (SBI) is the primary ingredient in a novel medical food $\left(\right.$ EnteraGam $\left.^{\circledR}\right)$ being evaluated in a number of GI disorders. SBI is composed of $\geq 90 \%$ pure protein with significant amounts of essential amino acids (Table 1). Over half of the protein content is in the form of immunoglobulins in which $\mathrm{IgG}$ constitutes the major isotype or class. The product also contains other proteins and peptides that reflect the composition of plasma and are similar to serum proteins found in colostrum and milk but does not contain casein, whey, or lactose. ${ }^{9}$ Studies in animals and human beings provide evidence that SBI is safe, improves nutritional status, has positive effects on various biomarkers of intestinal disease, and benefits patients with inflammatory bowel disease (IBD), irritable bowel syndrome with diarrhea (IBS-D), or human immunodeficiency virus (HIV)-associated enteropathy. ${ }^{10,11}$

Table I Amino acid composition of proteins within SBI

\begin{tabular}{ll}
\hline Amino acid & Mean \pm SD $(\mathbf{m g})^{*}$ \\
\hline Alanine & $204.1 \pm 1.2$ \\
Arginine & $236.4 \pm 0.6$ \\
Asparagine/aspartic acid & $417.8 \pm 3.7$ \\
Cystine & $107.0 \pm 2.4$ \\
Glutamine/glutamic acid & $512.8 \pm 3.3$ \\
Glycine & $191.4 \pm 0.3$ \\
Histidine & $111.2 \pm 0.8$ \\
Isoleucine & $138.9 \pm 0.6$ \\
Leucine & $367.8 \pm 0.9$ \\
Lysine & $320.8 \pm 3.4$ \\
Methionine & $47.3 \pm 1.2$ \\
Phenylalanine & $206.5 \pm 1.4$ \\
Proline & $265.3 \pm 2.1$ \\
Serine & $414.2 \pm 5.6$ \\
Threonine & $360.5 \pm 2.7$ \\
Tryptophan & $94.0 \pm 2.0$ \\
Tyrosine & $241.3 \pm 0.7$ \\
Valine & $373.5 \pm 3.3$ \\
\hline
\end{tabular}

Notes: *Represents the amount of amino acid (mg; mean $+/-\mathrm{SD})$ contained in $5 \mathrm{~g}$ of $\mathrm{SBI}$, as determined from quantitative testing of seven manufacturing lots.

Abbreviations: SBI, serum-derived bovine immunoglobulin/protein isolate; SD, standard deviation.
The purpose of the current study was to evaluate the absorption and safety of SBI in normal, healthy adult volunteers. Overall absorption was assessed by measuring the increase in amino acids in the blood following a single administration of one of three doses ( $5 \mathrm{~g}, 10 \mathrm{~g}$, or $20 \mathrm{~g}$ ) of SBI. Stool specimens from each subject were analyzed for the presence of bovine IgG prior to and after ingestion of SBI up to 14 days. The safety of the product was evaluated by recording adverse events (AEs) and testing for the presence of bovine $\mathrm{IgG}$ in the blood.

\section{Methods}

\section{Study population}

Male and nonpregnant female adult volunteers aged $\geq 18$ years who had a body mass index of $\geq 18 \mathrm{~kg} / \mathrm{m}^{2}$ and $\leq 32 \mathrm{~kg} / \mathrm{m}^{2}$ with no history of allergy to beef or any ingredient in SBI were considered eligible for the study. The volunteers were also in good health and physical condition as determined by medical history and clinical laboratory tests prior to study commencement. The laboratory tests included serum creatinine, blood urea nitrogen, pre-albumin, albumin, glucose, alanine aminotransferase, aspartate aminotransferase, alkaline phosphatase, total bilirubin, electrolytes $\left(\mathrm{Na}^{+}\right.$, $\mathrm{K}^{+}$, and $\mathrm{Cl}^{-}$), calcium, cholesterol, low-density lipoprotein, high-density lipoprotein and triglycerides, complete blood count (hemoglobin, hematocrit, red blood cell count, white blood cell count with differential, and platelet), and urinalysis (pH, ketones, blood, glucose, protein). Volunteers who had positive test results for HIV or hepatitis B or C were excluded from participation. Volunteers who participated in another investigational study 30 days or donated blood 7 days prior to study commencement, were unable to comprehend or comply with the study protocol, and were unable to give informed consent were excluded as well.

\section{Study design}

This prospective outpatient study was composed of two phases: a double-blind phase and an open-label phase (Figure 1). The double-blind phase was a randomized, placebo-controlled, crossover design to evaluate the concentration of bovine IgG in plasma following the oral administration of SBI, amino acid profile, and safety parameters. The doses of SBI were selected from two human trials that demonstrated improvement in GI symptoms in patients with IBS-D (5 g/day and $10 \mathrm{~g} /$ day) or patients with HIV-associated enteropathy (5 g/day). ${ }^{10,11}$ A total daily dose of $20 \mathrm{~g}$ of SBI was included in the present study for further evaluation of safety. Subjects were required to fast overnight ( $\geq 8$ hours) prior to arriving 


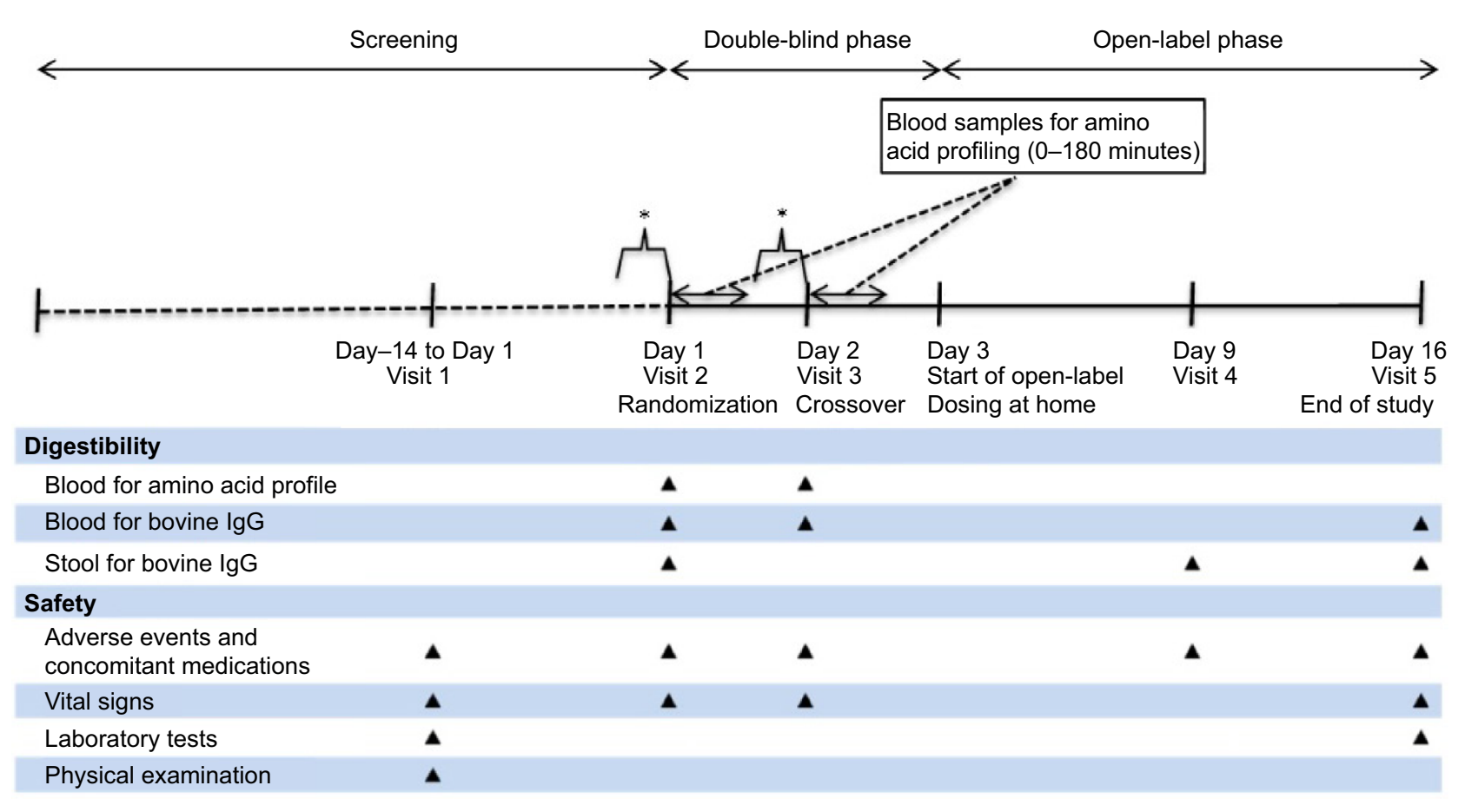

Figure I Study design and schedule of procedures.

Notes: A screening period was followed by study visits on days I, 2, 9 and 16. Triangles indicate the days on which study end points were assessed (except in the case of physical examinations that were symptom-directed after screening). Plasma samples were collected for amino acid analysis at time 0 minute and at 15 minutes, 30 minutes, 45 minutes, 60 minutes, 90 minutes, 120 minutes, and 180 minutes after administration of the investigational product on days I and 2 . Plasma for bovine lgG assessment was collected at time 0 minute and 90 minutes after administration of the investigational product on days I and 2 and once on day 16 . Stool samples for bovine IgG assessments were collected on days I, 9 and I6. *At least 8-hour fast prior to dosing.

Abbreviation: $\lg \mathrm{G}$, immunoglobulin G.

at the clinic on day 1 when they were randomized to receive either placebo (dextrose) or EnteraGam (each packet contained $5 \mathrm{~g}$ of SBI, dextrose, and a trace amount of sunflower lecithin) dissolved in $240 \mathrm{~mL}$ of water at an SBI dose level of $5 \mathrm{~g}, 10 \mathrm{~g}$, or $20 \mathrm{~g}$. Subjects were not allowed to consume water 1 hour before or 1 hour after administration of the investigational product (dextrose or EnteraGam); food was not allowed for at least 3 hours following the administration. The process was repeated for day 2 with another overnight fast ( $\geq 8$ hours), followed by oral administration of the matching dose of the investigational product not received the previous day (ie, subjects who received $5 \mathrm{~g}, 10 \mathrm{~g}$, or $20 \mathrm{~g}$ of SBI on day 1 received the matching dose of placebo on day 2, and subjects who received $5 \mathrm{~g}, 10 \mathrm{~g}$, or $20 \mathrm{~g}$ of placebo on day 1 received the matching dose of SBI on day 2). Serial blood samples for amino acid analysis were collected on day 1 and day 2 immediately before (time 0 ) and at 15 minutes, 30 minutes, 45 minutes, 60 minutes, 90 minutes, 120 minutes, and 180 minutes after administration of the investigational product. Blood samples for the assessment of bovine $\operatorname{IgG}$ were collected immediately before and 90 minutes following administration of the investigational product on day 1 and day 2. A baseline stool sample was collected prior to dosing on day 1 ; if the sample could not be collected on day 1 , then it was provided by the subject on day 2. Vital signs (blood pressure, heart rate, and oral temperature) were monitored at the screening visit, check-in on day 1 and day 2, and 3 hours following administration of the investigational product on day 1 and day 2.

The open-label phase of the study included BID dosing of EnteraGam for 14 days (through study day 16) to further evaluate the safety parameters and digestibility of bovine IgG. All the subjects initiated an open-label dosing of SBI on day 3. Subjects were instructed to consume divided portions of the SBI dose BID in $120 \mathrm{~mL}$ of water or noncaloric flavored water (ie, $2.5 \mathrm{~g}$ BID; $5 \mathrm{~g}$ BID; and $10 \mathrm{~g}$ BID). A single blood sample for the assessment of bovine $\operatorname{IgG}$ after multiple doses was collected on day 16. Additional stool samples for the assessment of bovine IgG were collected on day 9 and day 16 (end of the study). Safety monitoring was performed throughout the study.

\section{Amino acid analysis}

Plasma amino acid analysis was conducted by liquid chromatography-electrospray-tandem mass spectrometry (LC-ESIMS/MS) using an Agilent 1200/6460 Triple-Quadrupole LC/ MS system (Santa Clara, CA, USA). Standards and $25 \mu \mathrm{L}$ of plasma were processed using an EZ:faast ${ }^{\mathrm{TM}}$ (Phenomenex, 
Torrance, CA, USA) analysis kit for analyzing physiological amino acids by LC-MS. ${ }^{12}$

Amino acids quantified include all of those contained in SBI (Table 1) along with citrulline and ornithine. Blood samples for amino acid analysis were taken immediately before (time 0 ) and at 15 minutes, 30 minutes, 45 minutes, 60 minutes, 90 minutes, 120 minutes, and 180 minutes following administration of the investigational product.

\section{Detection of bovine $\lg G$ in plasma and stool}

Plasma samples were tested for bovine IgG content using a commercially available enzyme-linked immunosorbent assay (ELISA) kit with a sheep polyclonal antibody that specifically reacts to bovine IgG heavy chain (ELISA; Kit E11-118; Bethyl Laboratories, Inc., Montgomery, TX, USA). Bovine IgG was quantified in human plasma samples with minor modifications according to the manufacturer's instructions. A standard curve was generated by the addition of known concentrations of lyophilized bovine IgG (product \#I5506; Sigma-Aldrich, St. Louis, MO, USA) to commercially available normal human plasma (product \#23D00; SeraCare Life Sciences, Milford, MA, USA). All standards and samples were diluted $(1: 5)$ in a standard dilution buffer prior to the assay. The reaction time of 3,3',5,5'-tetramethylbenzidine with samples and standards was increased from 30 minutes to 60 minutes, which improved the absorbance range across the standard curve. Preliminary experiments with the modified assay established that the limit of quantification (LOQ) of bovine IgG in diluted plasma samples was $3.8 \mathrm{ng} / \mathrm{mL}$ (ELISA kit lot \#140821) and $4.6 \mathrm{ng} / \mathrm{mL}$ (ELISA kit lot \#140605).

Stool samples were divided into two portions: one aliquot was processed to determine the bovine $\mathrm{IgG}$ content and the other aliquot was immediately frozen and stored at $-80^{\circ} \mathrm{C}$. The frozen stool aliquot was subsequently processed to determine fecal dry weight by measuring $\sim 1 \mathrm{~g}$ of the stool, which was transferred to a drying oven and maintained at $120^{\circ} \mathrm{C}$ until no change in sample weight was observed over a 24-hour period. The remaining sample was weighed and recorded as sample fecal dry weight. For the analysis of bovine $\mathrm{IgG}, \sim 1 \mathrm{~g}$ of stool sample was mixed with $5 \mathrm{~mL}$ of cold Tris-buffered saline, vortexed for 1 minute, and homogenized for 30 seconds using an Omni Tissue Homogenizer with a clean, disposable Hard Tissue Omni Tip ${ }^{\mathrm{TM}}$ Plastic Homogenizing Probes $(7 \mathrm{~mm} \times 110 \mathrm{~mm})$. Homogenized samples were then centrifuged at $4^{\circ} \mathrm{C}, 1500 \times g$ for 15 minutes to pellet remaining solids in the stool samples before harvesting the supernatant, which was stored at $-70^{\circ} \mathrm{C}$ until shipped on dry ice for analysis. Bovine IgG in stool samples was quantified by a custom-developed ELISA utilizing a goat polyclonal antibody that specifically reacts to bovine IgG heavy and light chains with minimum reactivity to human, mouse, and rat (Bethyl Laboratories, Inc.). Preliminary experiments with the custom assay established that the LOQ of bovine IgG in human stool homogenate was $2.7 \mathrm{pg} / \mathrm{mg}$ dry weight.

\section{Safety assessment}

The safety of SBI was evaluated in all subjects who consumed at least one packet of the investigational product. It was assessed by conducting physical examinations, evaluating vital signs, performing clinical laboratory testing, and monitoring AEs following oral administration of SBI. AEs were coded using the MedDRA coding dictionary and monitored for all subjects from the time of study initiation (informed consent) through the last administration of the investigational product. Therapy-emergent AEs (TEAE) were defined as any event with a start date occurring on or after first dose date of the investigational product or, if preexisting, worsening after first dose date of the investigational product. The study investigator was solely responsible for determining the relationship of an AE with the investigational product based on all the available information at the time of event recording, including any preexisting medical condition(s).

A physical examination, including a comprehensive chemistry panel, complete blood count with differential, and urinalysis, was performed during the screening visit. Chemistry and hematology laboratory parameters were repeated at the end of the study visit (day 16). Symptom-directed physical examinations were performed at the study visits (ie, days 1, 2, 9, and 16) and for unscheduled clinic visits as needed. Subject-reported concomitant medications taken during the study were recorded at each visit.

\section{Statistical methods}

Following a single administration of SBI ( $5 \mathrm{~g}, 10 \mathrm{~g}$, or $20 \mathrm{~g})$ or placebo, plasma amino acid levels were quantitated as described earlier. Differences between the SBI dose groups and placebo were analyzed by comparing $C_{\max }$ and area under the curve (AUC) from 0 minutes to 180 minutes $\left(\mathrm{AUC}_{0-180}\right)$. The $C_{\max }$ and AUC were estimated using the post-administration amino acid responses over a 3-hour sampling interval and analyzed using a mixed model analysis of covariance (ANCOVA) technique appropriate for a two-period crossover design. A 95\% confidence interval and the associated $p$-value 
for the least square (LS) means between the SBI groups (test) and placebo were provided for the amino acid response profiles. One subject from the $20 \mathrm{~g}$ group was excluded from the amino acid analysis due to protocol deviation. A sensitivity analysis was also conducted across participant response data within group, where data flagged as possible "outliers" were excluded from subsequent analyses. The method for outlier detection used a robust regression, leverage-point detection analysis, identifying outliers as data points with a projected Mahalanobis distance $>2$.

Differences in the mean change of stool bovine IgG concentrations between test doses of SBI (2.5 g BID; $5 \mathrm{~g}$ BID; $10 \mathrm{~g}$ BID) collected at day 9 and day 16 and corresponding baseline were analyzed using a mixed covariate-adjusted model for paired data approach.

Baseline for all efficacy and safety variables was defined as the procedure performed during the screening visit or pre-dose on day 1, whichever provided the last pre-therapy assessment.

All statistical analyses were performed using $\mathrm{SAS}^{\oplus}$ Version 9.3. Except where noted, all statistical tests were two sided and performed at an alpha value of 0.05 significance. No corrections of multiple testing were performed, and $p$-values were rounded to four decimal places.

\section{Ethics, consent, and permissions}

The research protocol was approved by the Schulman Associates Institutional Review Board, Inc. (protocol ID: EH4001). Eligible participants were enrolled in the study after collecting written informed consent. This study was also registered with ClinicalTrials.gov (NCT02017405) on December 10, 2013.

\section{Results}

\section{Subject disposition and demographics}

A total of 47 individuals were screened in this study, of whom 42 subjects were enrolled and randomized at two study sites in NC, USA, between November 2013 and March 2014. One subject withdrew consent after a single $20 \mathrm{~g}$ placebo dose on day 1 , leaving a total of 41 subjects who received SBI $(5 \mathrm{~g}, \mathrm{n}=18 ; 10 \mathrm{~g}, \mathrm{n}=12 ; 20 \mathrm{~g}, \mathrm{n}=11)$ during the doubleblind (crossover) phase (Table 2). Dosing errors occurred in a total of six subjects at one site during this phase of the study. Specifically, four subjects assigned to receive $10 \mathrm{~g}$ SBI received $5 \mathrm{~g}$ SBI instead and two subjects assigned to receive $20 \mathrm{~g}$ SBI actually received $10 \mathrm{~g}$ SBI. Each of these subjects continued with the assigned dose of SBI during the 14-day, open-label phase of the study. As a result, six new subjects were added to the double-blind phase to ensure $\sim 12$ subjects per SBI group. A total of 38 of the 41 subjects were $>80 \%$ compliant with the investigational product during the open-label phase. Baseline demographics of the subjects were comparable across the SBI groups (Table 3). The mean age of the healthy subjects was 40.2 years; $55 \%$ were male and $59 \%$ were White.

\section{Plasma amino acid profile after ingestion of SBI}

The postprandial absorption of the protein within SBI was assessed following an overnight fast by measuring plasma concentrations of amino acids after a single administration of one of three doses $(5 \mathrm{~g}, 10 \mathrm{~g}$, or $20 \mathrm{~g})$. As shown in Figure 2, the calculated $\mathrm{AUC}_{0-180}$ for both total (Figure 2A)

Table 2 Disposition of study subjects

\begin{tabular}{|c|c|c|c|c|c|c|c|}
\hline \multirow[t]{2}{*}{ Description } & \multicolumn{3}{|c|}{$\begin{array}{l}\text { Placebo-controlled, double-blind, } \\
\text { crossover phase } \\
\text { (Day I and day 2) }\end{array}$} & \multicolumn{3}{|c|}{$\begin{array}{l}\text { Open-label phase } \\
\text { (Days 3-16) }\end{array}$} & \multirow{2}{*}{$\begin{array}{l}\text { Overall } \\
\text { (Days I-16) } \\
\text { Study total } \\
\text { (N) }\end{array}$} \\
\hline & $\begin{array}{l}\text { SBI } 5.0 \mathrm{~g} \\
\text { QD (N) }\end{array}$ & $\begin{array}{l}\text { SBI } 10.0 \mathrm{~g} \\
\text { QD (N) }\end{array}$ & $\begin{array}{l}\text { SBI } 20.0 \mathrm{~g} \\
\text { QD (N) }\end{array}$ & $\begin{array}{l}\text { SBI } 5.0 \text { g/day } \\
(2.5 \mathrm{~g} \text { BID) }(\mathrm{N})\end{array}$ & $\begin{array}{l}\text { SBI } 10.0 \text { g/day } \\
(5.0 \text { g BID) (N) }\end{array}$ & $\begin{array}{l}\text { SBI } 20.0 \text { g/day } \\
(10.0 \mathrm{~g} \mathrm{BID})(\mathrm{N})\end{array}$ & \\
\hline $\begin{array}{l}\text { Subjects participating in the } \\
\text { study }\end{array}$ & 18 & 12 & 12 & 14 & 14 & 13 & 42 \\
\hline $\begin{array}{l}\text { Subjects completing 2-day } \\
\text { double-blind, crossover period }\end{array}$ & 18 & 12 & $11 *$ & - & - & - & $4 I^{*}$ \\
\hline $\begin{array}{l}\text { Subjects completing 14-day } \\
\text { open-label period }\end{array}$ & - & - & - & $12^{\# / 14}$ & $14 / 14$ & $13 / 13$ & $39 / 41$ \\
\hline Subjects completing: & & & & & & & \\
\hline Plasma amino acid analysis & 18 & 12 & 11 & - & - & - & 41 \\
\hline Plasma lgG evaluation & 18 & 12 & 11 & 14 & 14 & 13 & 41 \\
\hline Stool IgG evaluation & - & - & - & 7 & 7 & 7 & $21^{\ddagger}$ \\
\hline
\end{tabular}

Notes: Dosing errors occurred in six subjects during the double-blind, crossover phase. Four subjects assigned to $10 \mathrm{~g}$ of SBI received $5 \mathrm{~g}$ of SBI and two subjects assigned to $20 \mathrm{~g}$ of SBI received $10 \mathrm{~g}$ of SBI. These six subjects continued with the assigned dose of SBI during the I4-day, open-label phase of the study. An additional six subjects were added to the 2-day, double-blind, crossover phase. ${ }^{\circ}$ One subject withdrew consent on day I after a single placebo dose; therefore, only $4 \mathrm{I}$ of 42 subjects received

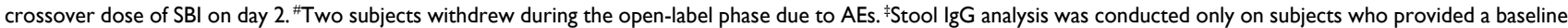
stool sample prior to receiving an active dose of SBI.

Abbreviations: AE, adverse event; BID, twice daily; IgG, immunoglobulin G; QD, once daily; SBI, serum-derived bovine immunoglobulin/protein isolate. 
Table 3 Baseline demographics

\begin{tabular}{lllll}
\hline Description & SBI 5.0 g QD; N (\%) & SBI I0.0 g QD; N (\%) & SBI 20.0 g QD; N (\%) & All groups; N (\%) \\
\hline $\begin{array}{l}\text { Total subjects } \\
\text { Sex }\end{array}$ & $18(100)$ & $12(100)$ & $12(100)$ & $42(100)$ \\
$\quad$ Female & $10(56)$ & $6(50)$ & $7(58)$ & $23(55)$ \\
$\quad$ Male & $8(44)$ & $6(50)$ & $5(42)$ & $19(45)$ \\
Race & $7(39)$ & $9(75)$ & $9(75)$ & $25(59)$ \\
$\quad$ White & $10(56)$ & $3(25)$ & $2(17)$ & $15(36)$ \\
$\quad$ Black or African American & $1(6)$ & $0(0)$ & $1(8)$ & $2(5)$ \\
$\quad$ Asian & $17(94)$ & $12(100)$ & $12(100)$ & $41(98)$ \\
Ethnicity & $1(6)$ & $0(0)$ & $0(0)$ & $1(2)$ \\
$\quad$ Non-Hispanic/Latino & $37.3 \pm 9.66$ & $45.0 \pm 16.64$ & $39.9 \pm 13.26$ & $40.2 \pm 13.06$ \\
$\quad$ Hispanic/Latino & 34.5 & 39.0 & 39.0 & 38.0 \\
Age (years) & $24-56$ & $27-69$ & $18-58$ & $18-69$ \\
$\quad$ Mean \pm SD & Median & & \\
Minimum-maximum & & & \\
\hline
\end{tabular}

Abbreviations: QD, once daily; SBI, serum-derived bovine immunoglobulin/protein isolate; SD, standard deviation.

and essential (Figure 2B) amino acids following overnight fasting increased as the amount of SBI ingested was increased from $5 \mathrm{~g}$ to $20 \mathrm{~g}$. The calculated $\mathrm{AUC}_{0-180}$ for total amino acids following the ingestion of a single dose of $5 \mathrm{~g}, 10 \mathrm{~g}$, or $20 \mathrm{~g}$ of SBI was $15.61 \mu \mathrm{mol} / \mathrm{mL} \times \mathrm{min}$, $45.14 \mu \mathrm{mol} / \mathrm{mL} \times \mathrm{min}$, and $107.18 \mu \mathrm{mol} / \mathrm{mL} \times \mathrm{min}$, respectively. The calculated $\mathrm{AUC}_{0-180}$ for essential amino acids following the ingestion of a single dose of $5 \mathrm{~g}, 10 \mathrm{~g}$, or $20 \mathrm{~g}$ of SBI was $14.89 \mu \mathrm{mol} / \mathrm{mL} \times \min , 26.92 \mu \mathrm{mol} / \mathrm{mL} \times \min$, and $47.53 \mu \mathrm{mol} / \mathrm{mL} \times \mathrm{min}$, respectively. The $\mathrm{AUC}_{0-180}$ for tryptophan (Figure $2 \mathrm{C}$ ) was $1.12 \mu \mathrm{mol} / \mathrm{mL} \times \min , 3.08 \mu \mathrm{mol} /$ $\mathrm{mL} \times \mathrm{min}$, and $3.74 \mu \mathrm{mol} / \mathrm{mL} \times \min$ for the $5 \mathrm{~g}, 10 \mathrm{~g}$, or $20 \mathrm{~g}$ dose of SBI, respectively. Statistical analysis of these AUC data revealed that, for each dose of SBI, there was a significant $(p<0.02)$ amount of amino acid absorption in terms of essential amino acids when compared to the placebo group. Absorption of total amino acids was statistically significant $(p<0.02)$ at the $10 \mathrm{~g}$ and $20 \mathrm{~g}$ doses of SBI but not at the lowest dose. In terms of the individual amino acids quantified, some showed the same statistically significant difference over placebo with increasing SBI dose while others did not. Absorption of the essential amino acid tryptophan was statistically significant $(p<0.02)$ for each dose of SBI administered (Figure 2C).

The plasma amino acid concentration-time curve plots depicting amino acid absorption and used for calculation of AUC (0-180 min) values are shown in Figure 3. Following the ingestion of SBI, an increase in total and essential amino acids was observed in all SBI groups with peak plasma concentrations appearing at 30-45 minutes for the lower doses (ie, $5 \mathrm{~g}$ and $10 \mathrm{~g}$ ), but delayed until 60-120 minutes for the $20 \mathrm{~g}$ group. The peak concentration ( $\mathrm{LS}$ mean $C_{\max }$ ) for total amino acids following the ingestion of a single dose of $5 \mathrm{~g}, 10 \mathrm{~g}$, or $20 \mathrm{~g}$ of SBI was $3.38 \mu \mathrm{mol} / \mathrm{min}, 3.58 \mu \mathrm{mol} /$ $\mathrm{min}$, and $3.54 \mu \mathrm{mol} / \mathrm{min}$, respectively. The peak LS mean $C_{\max }$ for essential amino acids following the ingestion of a single dose of $5 \mathrm{~g}, 10 \mathrm{~g}$, or $20 \mathrm{~g}$ of SBI was $1.19 \mu \mathrm{mol} / \mathrm{min}$, $1.34 \mu \mathrm{mol} / \mathrm{min}$, and $1.34 \mu \mathrm{mol} / \mathrm{min}$, respectively. Plasma concentrations of tryptophan followed a similar profile with increasing doses of SBI resulting in longer times to peak concentration. In addition, plasma tryptophan levels remained above baseline through 180 minutes following the $20 \mathrm{~g}$ dose of SBI $(p<0.01)$ but returned to baseline earlier in the $5 \mathrm{~g}$ and $10 \mathrm{~g}$ SBI groups. Tryptophan peak LS mean $C_{\max }$ following the ingestion of a single dose of $5 \mathrm{~g}, 10 \mathrm{~g}$, or $20 \mathrm{~g}$ of SBI was $0.08 \mu \mathrm{mol} / \mathrm{min}, 0.10 \mu \mathrm{mol} / \mathrm{min}$, and $0.10 \mu \mathrm{mol} / \mathrm{min}$, respectively.

\section{Bovine lgG in stool}

To determine the extent to which the IgG component of SBI is degraded chemically and/or enzymatically during transit through the GI tract, stool samples collected at day 1 (baseline), day 9, and at the end of the study (day 16) were tested for the presence of bovine IgG. When compared to baseline samples, significantly higher amounts of bovine IgG were detected in stool samples obtained on day 9 for subjects ingesting SBI daily at levels of $5 \mathrm{~g}(103.8 \mathrm{pg} / \mathrm{mg}$, $p<0.02), 10 \mathrm{~g}(139.2 \mathrm{pg} / \mathrm{mg}, p<0.004)$, and $20 \mathrm{~g}(146.7 \mathrm{pg} /$ $\mathrm{mg}, p<0.0003)$. Similar results were obtained on day 16 following the daily ingestion of SBI at levels of $5 \mathrm{~g}(100.79$ $\mathrm{pg} / \mathrm{mg}, p<0.02), 10 \mathrm{~g}(160.20 \mathrm{pg} / \mathrm{mg}, p<0.002)$, and $20 \mathrm{~g}$ $(111.59 \mathrm{pg} / \mathrm{mg}, p<0.003)$. These results confirm that bovine IgG is capable of surviving the passage through the entirety of the GI tract. 
A

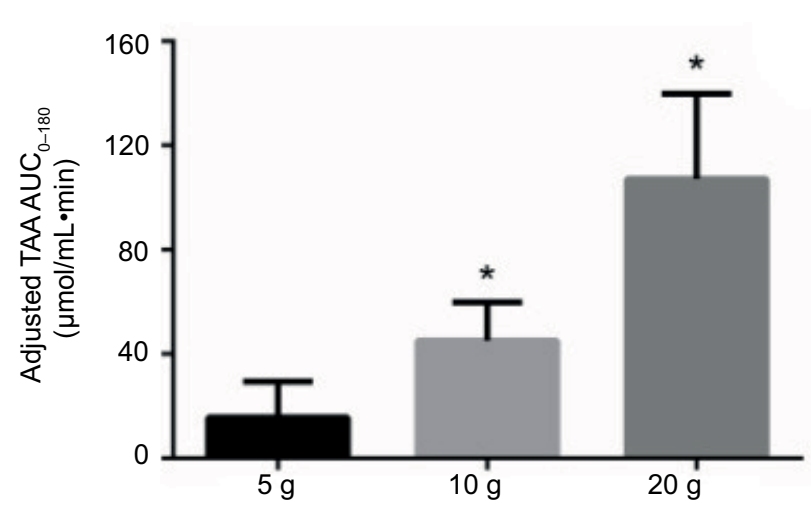

SBI Administered

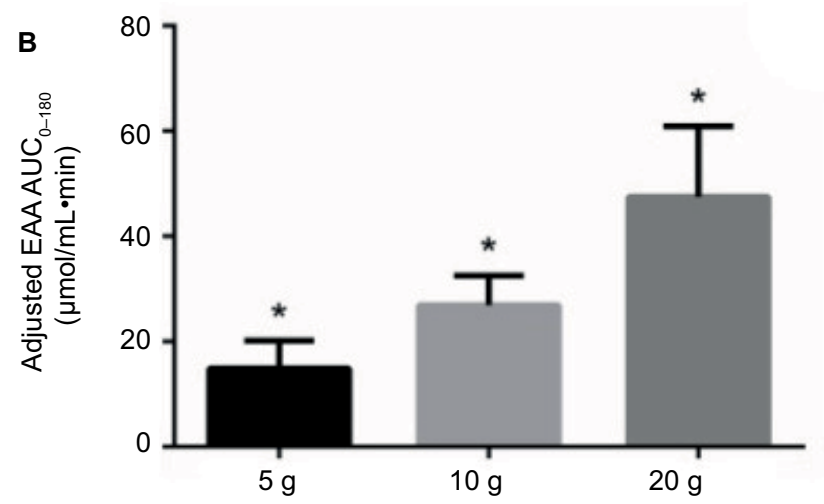

SBI Administered

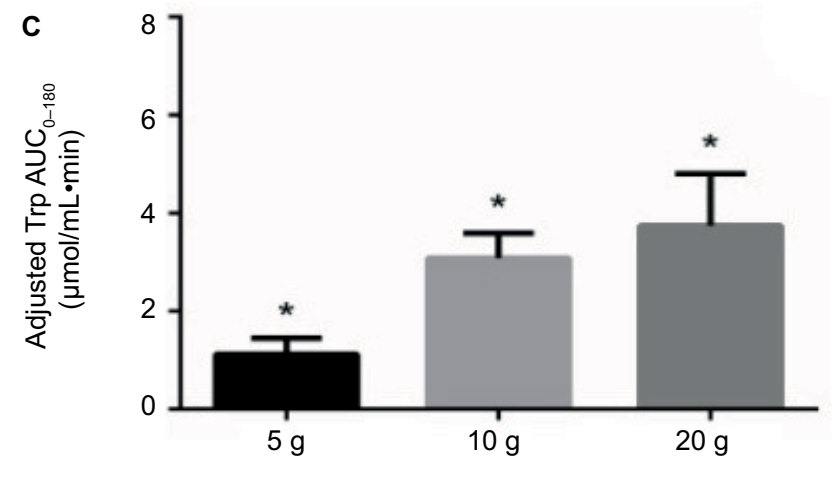

SBI Administered

Figure $2 \mathrm{AUC}_{0-180}(\mathrm{nmol} / \mathrm{mL} \times \mathrm{min})$ following ingestion of $\mathrm{SBI}$ at $5 \mathrm{~g}, 10 \mathrm{~g}$, or $20 \mathrm{~g}$ dose levels (LS mean adjusted for levels from matching placebo dose [test minus placebo] using a mixed model for crossover data) for total amino acids (A), essential amino acids (B), and tryptophan (C).

Note: ${ }^{*} p<0.02$ versus placebo at matching dose level.

Abbreviations: $\mathrm{AUC}_{0-180}$, area under the plasma amino acid concentration-time curve from time 0 to 180 minutes; EAA, essential amino acids; LS, least square; SBI, serumderived bovine immunoglobulin/protein isolate; TAA, total amino acids; Trp, tryptophan.

\section{Safety}

The "safety population" consisted of randomized subjects who received at least one dose of the investigational product. An overall summary of subjects reporting TEAEs is presented in Table 4. A total of 20 subjects experienced an AE during the study. These AEs were judged by the investigator as mild or moderate in intensity with no severe AEs or serious
A

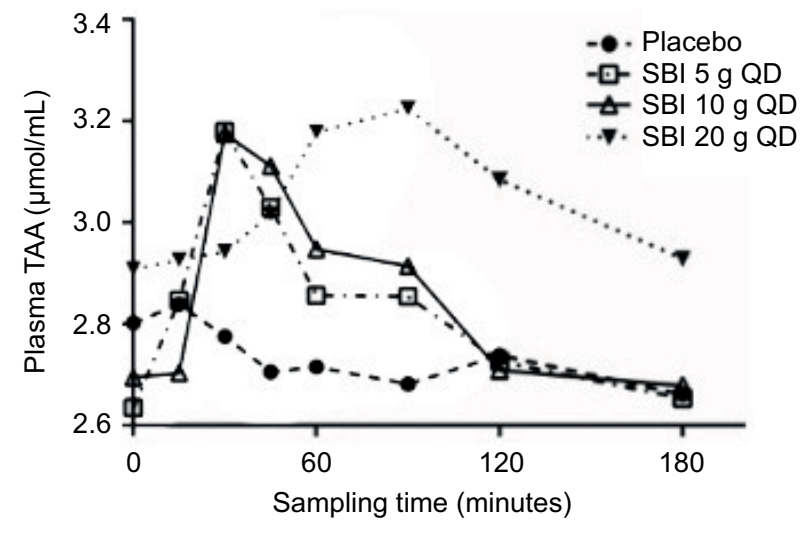

B

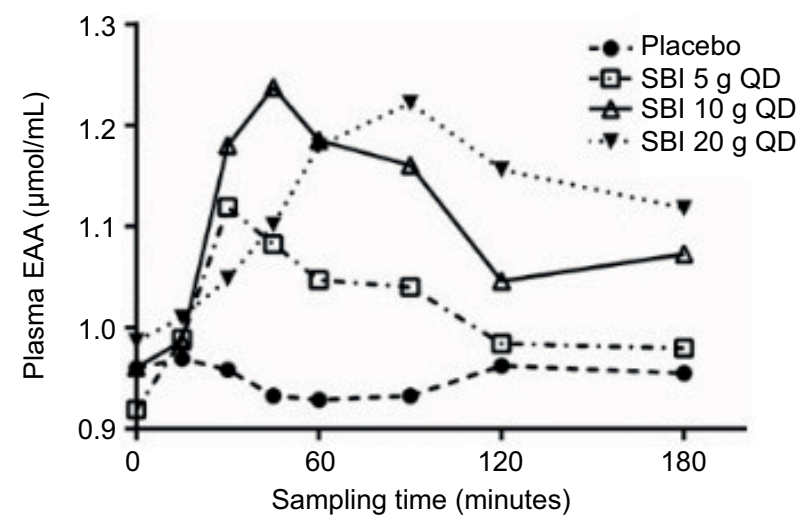

C

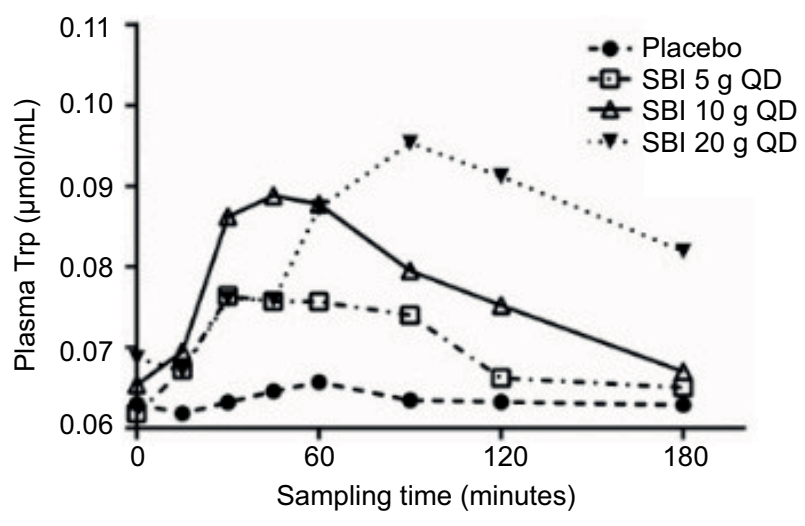

Figure 3 Mean plasma amino acid concentration-time curves for total amino acids (A), essential amino acids (B), and tryptophan (C) during a 3-hour post-ingestion period after a single dose of $5 \mathrm{~g}, 10 \mathrm{~g}$, or $20 \mathrm{~g}$ of SBI or placebo.

Abbreviations: EAA, essential amino acids; $Q D$, once daily; $S B I$, serum-derived bovine immunoglobulin/protein isolate; TAA, total amino acids; Trp, tryptophan.

AEs (SAEs) reported. The number of subjects reporting TEAEs at an incidence of $>2 \%$ during the study included: abdominal cramps (four), constipation (three), bloating (two), diarrhea (two), flatulence (two), abdominal pain (one), and nausea (one). There was no discernable pattern of AEs with increasing dose. Four subjects experienced an AE that was considered to be related to SBI during the placebo-controlled, 
Table 4 Adverse events

\begin{tabular}{|c|c|c|c|c|c|c|c|c|}
\hline \multirow[t]{2}{*}{ Safety population* } & \multicolumn{4}{|c|}{$\begin{array}{l}\text { Placebo-controlled, double-blind, crossover phase } \\
\text { (Day I and day 2) }\end{array}$} & \multicolumn{3}{|c|}{$\begin{array}{l}\text { Open-label phase } \\
\text { (Days 3-16) }\end{array}$} & \multirow{2}{*}{$\begin{array}{l}\text { Overall } \\
(\text { Days I-16) } \\
\text { SBI total } \\
(N=4 I)\end{array}$} \\
\hline & $\begin{array}{l}\text { Placebo } \\
\text { QD }(\mathrm{N}=42)\end{array}$ & $\begin{array}{l}\text { SBI } 5 \mathrm{~g} \\
\text { QD }(\mathrm{N}=18)\end{array}$ & $\begin{array}{l}\text { SBI } 10 \mathrm{~g} \\
\mathrm{QD}(\mathrm{N}=12)\end{array}$ & $\begin{array}{l}\text { SBI } 20 \mathrm{~g} \\
\text { QD }(\mathrm{N}=\mathrm{II})\end{array}$ & $\begin{array}{l}\text { SBI } 2.5 \mathrm{~g} \\
\text { BID }(\mathrm{N}=14)\end{array}$ & $\begin{array}{l}\text { SBI } 5 \text { g BID } \\
(N=14)\end{array}$ & $\begin{array}{l}\text { SBI } 10 \mathrm{~g} \\
\text { BID }(\mathrm{N}=13)\end{array}$ & \\
\hline $\begin{array}{l}\text { Number of subjects with at } \\
\text { least one TEAE }\end{array}$ & 1 & 4 & 0 & 3 & 7 & 5 & 5 & 20 \\
\hline \multicolumn{9}{|l|}{ TEAEs by maximum severity } \\
\hline Mild & 1 & 1 & 0 & 3 & 4 & 3 & 3 & 13 \\
\hline Moderate & 0 & 3 & 0 & 1 & 4 & 2 & 3 & 11 \\
\hline Severe & 0 & 0 & 0 & 0 & 0 & 0 & 0 & 0 \\
\hline SAEs & 0 & 0 & 0 & 0 & 0 & 0 & 0 & 0 \\
\hline $\begin{array}{l}\text { Number of subjects with } \\
\text { one or more TEAEs related } \\
\text { to nutritional therapy }\end{array}$ & 0 & 1 & 0 & 3 & 4 & 0 & 2 & 8 \\
\hline Abdominal cramps & 0 & 0 & 0 & 0 & 3 & 0 & 1 & 4 \\
\hline Constipation & 0 & 0 & 0 & 0 & 2 & 0 & 1 & 3 \\
\hline Bloating & 0 & 0 & 0 & I & I & 0 & 0 & 2 \\
\hline Diarrhea & 0 & 1 & 0 & 0 & I & 0 & 0 & 2 \\
\hline Flatulence & 0 & 0 & 0 & 2 & 0 & 0 & 0 & 2 \\
\hline Abdominal pain & 0 & 1 & 0 & 0 & 0 & 0 & 0 & 1 \\
\hline Nausea & 0 & 0 & 0 & 0 & 0 & 0 & I & 1 \\
\hline
\end{tabular}

Notes: *Safety analysis set consisted of all randomized subjects who received at least one dose of double-blind investigational nutritional therapy. "Figures in the table refer to the number of subjects experiencing one or more AEs. Multiple AEs within the same preferred term or system organ class that were experienced by the same subject were counted only once. Subjects that experienced an AE on Day I and another AE on day 2 of the placebo-controlled phase were counted only once in the overall total. Abbreviations: $A E$, adverse event; BID, twice daily; $Q D$, once daily; SAE, serious AE; SBI, serum-derived bovine immunoglobulin/protein isolate; TEAE, therapy-emergent $A E$.

double-blind, 2-day, crossover phase; one in the $5 \mathrm{~g}$ SBI group (diarrhea and abdominal pain) and three subjects in the $20 \mathrm{~g}$ SBI group (flatulence and bloating). During the 14-day open-label phase, six subjects experienced an $\mathrm{AE}$ that was considered to be related to SBI: four subjects in the SBI 2.5 g BID group (abdominal cramps, constipation, bloating, and diarrhea) and two subjects in the SBI $10 \mathrm{~g}$ BID group (abdominal cramps, constipation, and nausea). Two subjects withdrew from the study due to an AE. Both subjects were in the SBI 5.0 g group: one discontinued due to abdominal cramps (subject 014-0002) and the other discontinued due to abdominal cramps, bloating, and diarrhea (subject 014-0012).

Of the 42 subjects (comprising a total of 205 plasma samples), only a single subject (subject 014-0002) showed plasma levels of bovine IgG above the LOQ $(4.6 \mathrm{ng} / \mathrm{mL})$. In that one subject, there were two plasma samples (time 0 minute and 90 minutes) following the administration of placebo on day 2 that showed quantifiable amounts of bovine $\operatorname{IgG}(25 \mathrm{ng} / \mathrm{mL}$ and $254 \mathrm{ng} / \mathrm{mL}$, respectively). No detectable levels of plasma bovine $\mathrm{IgG}$ were found at time 0 minute and 90 minutes following the administration of $5 \mathrm{~g}$ of SBI on day 1 or on day 9 following 6 additional days of dosing for this subject.

For the other 41 subjects, no quantifiable levels of bovine $\mathrm{IgG}$ levels were determined in plasma samples 90 minutes following the administration of a single dose of SBI on day 1 and day 2 or following multiple doses of SBI for up to 14 days.

\section{Discussion}

Early studies evaluating the oral administration of bovine serum or plasma protein preparations in experimentally challenged or weaning animals have consistently reported dramatic improvements in growth, food intake, and overall health status when compared to animals fed control diets. ${ }^{3,13}$ $\mathrm{SBI}$ is one such preparation that is rich in immunoglobulin content, particularly the IgG class. Recent studies of SBI in human beings have yielded similar results of efficacy in the finished product, which is currently available as a medical food ${ }^{9}$ and intended for conditions such as IBS-D,${ }^{10}$ IBD, ${ }^{9}$ and HIV-associated enteropathy. ${ }^{11}$ Indeed, in multiple clinical reports, the product has been shown to manage effectively the chronic loose and frequent stools found in these conditions, ${ }^{10,11,14-16}$ as well as to improve nutritional outcomes in pediatric malnutrition. ${ }^{17,18}$

The safety record of SBI is documented in the AE profile from those clinical studies, as well as the 22,000 or more patients that have ingested nearly 3 million doses of the commercial product, EnteraGam. It is important, nonetheless, to determine whether intact bovine protein, following oral administration, is capable of crossing the intestinal epithelium into the systemic circulation. 
In addition, demonstration of the survivability of immunoglobulins such as IgG throughout the entirety of the digestive tract would help to explain the positive results observed in patients with both small and large bowel disorders.

The current study evaluated the safety of SBI in normal, healthy adult volunteers as well as the absorption of amino acids from its constitutive protein. Subjects ingested a single dose of placebo or SBI at one of the three dose levels during the randomized, double-blind, crossover phase and continued on SBI BID for an additional 2 weeks. Plasma samples were collected for evaluating changes in amino acid levels following oral administration of SBI and for examining the potential for bovine IgG to appear in the systemic circulation. Bovine IgG surviving the transit through the digestive tract was determined from stool samples.

Following the administration of SBI, a significant dosedependent increase in the plasma AUC was observed for both total and essential amino acids. This finding was not surprising given the composition of SBI is $\sim 95 \%$ protein (w/w), which includes $\geq 50 \%$ IgG. ${ }^{19}$ Since IgG is inherently resistant to proteolytic digestion, it is plausible that $\sim 40 \%$ nonimmunoglobulin protein fraction of SBI was responsible for the majority of the increase in total amino acid levels that we observed. ${ }^{5,8}$ Inspection of the time course for the increase in amino acid levels in plasma showed delayed absorption (both total and essential amino acids) in the $20 \mathrm{~g}$ group in which peak concentrations appeared 90-120 minutes post dosing, as compared to the $5 \mathrm{~g}$ and $10 \mathrm{~g}$ groups, where peak levels occurred $\sim 30-45$ minutes. A few factors may have played a role in the delayed absorption: 1) the rate of gastric digestion and emptying which may be influenced by the volume and composition of the protein ingested and/or 2) a high concentration of amino acids may have saturated the transport system across the epithelial membrane.

Although significant digestion of the protein content of SBI occurred in these healthy subjects, which was consistent with previously reported results in other studies (detection of bovine IgG in fecal samples from human children or adults following oral administration of bovine plasma or colostrum preparations ${ }^{5-7,20-22}$ ), bovine $\operatorname{IgG}$ was detected in the stool from subjects on day 9 and day 16. A recent review of human studies in infants, children, and adults also reported that 12 of the 15 studies demonstrated that orally administered IgG derived from human or bovine serum, or bovine milk or colostrum, survives gastric exposure and resists proteolytic digestion in the stomach and the intestinal tract. ${ }^{8}$ Collectively, these studies demonstrate that a portion of bovine IgG survives GI transit following oral administration of protein fractions prepared from bovine serum, plasma, or colostrum. It is believed that the IgG fraction of SBI is responsible for the observed effects in patients with intestinal disorders, which is supported by the abovementioned observation that a specific amount of this class of immunoglobulins in SBI survives transit through the entirety of the GI tract. The extent of degradation of immunoglobulins within healthy volunteers versus patients with GI disorders is dictated by several factors that include not only the conditions present throughout the GI tract but also transit time and the intrinsic stability of the immunoglobulin proteins themselves.

This study is the first to evaluate in human beings the safety of SBI at multiple dose levels ranging as high as $20 \mathrm{~g} /$ day. Several previous studies were conducted to evaluate the clinical benefits and/or safety of bovine immunoglobulin preparations in human infants, ${ }^{23,24}$ children, ${ }^{17,18,20}$ and adults. ${ }^{5,7,21}$ In the current study, all the AEs reported were mild or moderate in intensity and were associated with some type of GI symptom. Only two subjects withdrew from the study due to AEs, and there were no SAEs reported. These results confirm and extend the findings of other studies regarding the safety of bovine immunoglobulin preparations ${ }^{17,18}$ and further document the safety of SBI at dose levels as high as $20 \mathrm{~g} /$ day.

Using our test method, we were unable to detect quantifiable levels of bovine IgG in plasma samples obtained from subjects 90 minutes after a single dose of SBI, or in plasma samples from subjects on day 16 after multiple daily doses of SBI. One subject showed quantifiable levels of plasma bovine IgG on day 2, both prior to and 90 minutes after receiving placebo. This subject received SBI on day 1 , but it is unlikely that the bovine IgG detected in plasma on day 2 was from the dose of SBI (5 g once daily [QD]) received on day 1 , since transit through the small intestine is typically completed by 6 hours in most individuals. ${ }^{25}$ In addition, it is highly unlikely that the bovine IgG from a single dose of SBI would appear and increase 10-fold in plasma during a narrow, 90-minute observation window 24 hours after ingestion. Furthermore, bovine IgG was not detected in plasma from 20 other subjects on day 2 after having received SBI on day 1 (5 g QD, $10 \mathrm{~g} \mathrm{QD}$, or $20 \mathrm{~g}$ QD) or in plasma samples from any subject on day 16 after receiving multiple daily doses of SBI. Collectively, these observations suggest that the detection of plasma IgG in the single subject described earlier is most likely due to mishandling of the plasma sample or some unknown substance in the plasma sample that confounded assay results. 
The immunoglobulins found in SBI have been shown to bind in vitro to many different microbial components, which is believed to provide the basis for the mechanism in which SBI imparts its benefits. Indeed, SBI binding has been confirmed for lipopolysaccharide, peptidoglycan, flagellin, and a number of other microbial antigens that could traverse a damaged intestinal barrier and cause activation of the intestinal immune system and disrupt immune balance and gut barrier function. ${ }^{19,26,27}$ While the mechanism of action of SBI has not been fully elucidated, the binding of antigens capable of inducing inflammation may prevent their passage into the lamina propria, thereby dampening potential immune responses in the gut-associated lymphoid tissue involved in disrupting intestinal homeostasis. Results from studies employing animal models of colitis have also provided results that are consistent with the hypothesis that SBI helps support intestinal homeostasis. ${ }^{28,29}$

It is also possible that other nutritive components in SBI are additive to or act synergistically with the activity of bovine IgG. For example, nutritional studies have shown that dietary supplementation with several amino acids (eg, arginine, glutamine, glutamate, leucine, and proline) modulate gene expression, enhance growth of the small intestine and skeletal muscle, and benefit immune cells. ${ }^{30,31}$ Such studies have led to the designation of these amino acids as "conditionally essential" during certain physiologic and pathologic conditions. ${ }^{31,32}$ It has also been reported that increased tryptophan catabolism through the kynurenine pathway, by indoleamine 2,3-dioxygenase-1 expressed by activated dendritic cells and monocytes or other enzymes associated with the intestinal microbiota, ${ }^{33}$ is associated with impaired differentiation and activity of T-cells, ${ }^{34,35}$ which may contribute to further gut barrier dysfunction, alterations in the gut microbiota, and immune activation that persist in states of intestinal disorders. This article also reports statistically significant increases in levels of tryptophan in plasma of subjects after consuming SBI, which possibly acts in combination with IgG to provide immune and gut barrier benefits observed in other studies..$^{10,11}$

\section{Conclusion}

Collectively, the findings in this study demonstrate that oral administration of SBI (EnteraGam) is safe at levels at least as high as $20 \mathrm{~g} /$ day and leads to increases in plasma essential amino acids with no appearance of bovine $\mathrm{IgG}$ in plasma. Our results also demonstrate levels of bovine IgG in stool samples, suggesting at least partial survival of IgG during transit through the GI tract in healthy volunteers.

\section{Acknowledgments}

The authors would like to thank Martin van Cleeff, MD, and Miroslav Gavazov, MD, for their role in recruitment of subjects and management of subjects during the study and Abigail Henderson, $\mathrm{PhD}$, for analysis of bovine IgG in plasma samples. This study was funded by Entera Health, Inc.

\section{Author contributions}

Audrey L Shaw, $\mathrm{PhD}$, is the guarantor of this article. All authors contributed toward data analysis, drafting and revising the paper and agree to be accountable for all aspects of the work.

\section{Disclosure}

ALS, BWP, CJD, DWM, and TPB are the employees of Entera Health, Inc. JEH, EMW, and GLK report no conflicts of interest in this work.

\section{References}

1. Hurley WL, Theil PK. Perspectives on immunoglobulins in colostrum and milk. Nutrients. 2011;3(4):442-474.

2. Gapper LW, Copestake DE, Otter DE, Indyk HE. Analysis of bovine immunoglobulin $\mathrm{G}$ in milk, colostrum and dietary supplements: a review. Anal Bioanal Chem. 2007;389(1):93-109.

3. Torrallardona D. Spray dried animal plasma as an alternative to antibiotics in weanling pigs - a review. Asian-Australasian J Anim Sci. 2010;23(1):131-148.

4. Pierce JL, Cromwell GL, Lindemann MD, Russell LE, Weaver EM. Effects of spray-dried animal plasma and immunoglobulins on performance of early weaned pigs. J Anim Sci. 2005;83(12): 2876-2885.

5. Roos N, Mahe S, Benamouzig R, Sick H, Rautureau J, Tome D. N15labeled immunoglobulins from bovine colostrum are partially resistant to digestion in human intestine. J Nutr. 1995;125(5):1238-1244.

6. Kelly CP, Chetham S, Keates S, et al. Survival of anti-Clostridium difficile bovine immunoglobulin concentrate in the human gastrointestinal tract. Antimicrob Agents Chemother. 1997;41(2):236-241.

7. Warny M, Fatimi A, Bostwick EF, et al. Bovine immunoglobulin concentrate-Clostridium difficile retains $C$. difficile toxin neutralising activity after passage through the human stomach and small intestine. Gut. 1999;44(2):212-217.

8. Jasion VS, Burnett BP. Survival and digestibility of orally-administered immunoglobulin preparations containing IgG through the gastrointestinal tract in humans. Nutr J. 2015;14:22.

9. EnteraGam ${ }^{\circledast}$ [product information]. Entera Health, Inc.; 2015. Available from: http://enteragam.com/assets/lib/EnteraGam_Product_Information.pdf. Accessed August 19, 2016.

10. Wilson D, Evans MD, Weaver E, Shaw AL, Klein GL. Evaluation of serum-derived bovine immunoglobulin protein isolate in subjects with diarrhea-predominant irritable bowel syndrome. Clin Med Insights Gastroenterol. 2013;6:49-60.

11. Asmuth DM, Ma ZM, Albanese A, et al. Oral serum-derived bovine immunoglobulin improves duodenal immune reconstitution and absorption function in patients with HIV enteropathy. AIDS. 2013;27(14):2207-2217.

12. Badawy AA. The EZ:Faast family of amino acid analysis kits: application of the GC-FID kit for rapid determination of plasma tryptophan and other amino acids. Methods Mol Biol. 2012;828:153-164. 
13. Kuchibhatla R, Petschow BW, Odle J, Weaver EM. Nutritional impact of dietary plasma proteins in animals undergoing experimental challenge and implications for patients with inflammatory bowel disorders: a meta-analysis. Adv Nutr. 2015;6(5):541-551.

14. Awad A, Jasion VS. Use of a nutritional therapy, serum-derived bovine immunoglobulin/protein isolate (SBI), to achieve improvement in two different cases of colitis. Gastrointest Dig Syst. 2015;5:274.

15. Good L, Rosario R, Panas R. New therapeutic option for irritable bowel syndrome: serum-derived bovine immunoglobulin. World J Gastroenterol. 2015;21(11):3361-3366.

16. Shafran I, Burgunder P, Wei D, Young HE, Klein G, Burnett BP. Management of inflammatory bowel disease with oral serum-derived bovine immunoglobulin. Therap Adv Gastroenterol. 2015;8(6):331-339.

17. Lembcke JL, Peerson JM, Brown KH. Acceptability, safety, and digestibility of spray-dried bovine serum added to diets of recovering malnourished children. J Pediatr Gastroenterol Nutr. 1997;25(4):381-384

18. Begin F, Santizo MC, Peerson JM, Torun B, Brown KH. Effects of bovine serum concentrate, with or without supplemental micronutrients, on the growth, morbidity, and micronutrient status of young children in a low-income, peri-urban Guatemalan community. Eur J Clin Nutr. 2008;62(1):39-50.

19. Petschow BW, Burnett B, Shaw AL, Weaver EM, Klein GL. Serumderived bovine immunoglobulin/protein isolate: postulated mechanism of action for management of enteropathy. Clin Exp Gastroenterol. 2014;7:181-190.

20. Pacyna J, Siwek K, Terry SJ, Roberton ES, Johnson RB, Davidson GP. Survival of rotavirus antibody activity derived from bovine colostrum after passage through the human gastrointestinal tract. J Pediatr Gastroenterol Nutr. 2001;32(2):162-167.

21. McClead RE Jr, Butler T, Rabbani GH. Orally administered bovine colostral anti-cholera toxin antibodies: results of two clinical trials. $\mathrm{Am}$ J Med. 1988;85(6):811-816.

22. Tacket CO, Binion SB, Bostwick E, Losonsky G, Roy MJ, Edelman R Efficacy of bovine milk immunoglobulin concentrate in preventing illness after Shigella flexneri challenge. Am J Trop Med Hyg. 1992;47(3):276-283.

23. Zinkernagel RM, Hilpert H, Gerber $H$. The digestion of colostral bovine immunoglobulins in infants. Experientia. 1972;28:741.
24. Hilpert H, Brussow H, Mietens C, Sidoti J, Lerner L, Werchau H. Use of bovine milk concentrate containing antibody to rotavirus to treat rotavirus gastroenteritis in infants. J Infect Dis. 1987;156(1):158-166.

25. Argenyi EE, Soffer EE, Madsen MT, Berbaum KS, Walkner WO. Scintigraphic evaluation of small bowel transit in healthy subjects: inter- and intrasubject variability. Am J Gastroenterol. 1995;90(6): 938-942.

26. Detzel CJ, Horgan A, Henderson AL, et al. Bovine immunoglobulin/ protein isolate binds pro-inflammatory bacterial compounds and prevents immune activation in an intestinal co-culture model. PLoS One 2015;10(4):e0120278.

27. Horgan A, Maas KJ, Henderson A, Detzel CJ, Weaver EM. Serumderived bovine immunoglobulin/protein isolate binds to pathogenassociated molecular patterns. FASEB J. 2014;128(Suppl 1):836.6.

28. Henderson AL, Brand MW, Darling RJ, et al. Attenuation of colitis by serum-derived bovine immunoglobulin/protein isolate in a defined microbiota mouse model. Dig Dis Sci. 2015;60(11):3293-3303.

29. Perez-Bosque A, Miro L, Maijo M, et al. Dietary intervention with serum-derived bovine immunoglobulins protects barrier function in a mouse model of colitis. Am J Physiol Gastrointest Liver Physiol. 2015;308(12):G1012-G1018.

30. Ziegler TR, Evans ME, Fernandez-Estivariz C, Jones DP. Trophic and cytoprotective nutrition for intestinal adaptation, mucosal repair, and barrier function. Annu Rev Nutr. 2003;23:229-261.

31. Wu G. Functional amino acids in nutrition and health. Amino Acids 2013;45(3):407-411.

32. Boza JJ, Maire J, Bovetto L, Ballevre O. Plasma glutamine response to enteral administration of glutamine in human volunteers (free glutamine versus protein-bound glutamine). Nutrition. 2000; 16(11-12):1037-1042.

33. Vujkovic-Cvijin I, Dunham RM, Iwai S, et al. Dysbiosis of the gut microbiota is associated with HIV disease progression and tryptophan catabolism. Sci Transl Med. 2013;5(193):193ra191.

34. Favre D, Mold J, Hunt PW, et al. Tryptophan catabolism by indoleamine 2,3-dioxygenase 1 alters the balance of TH17 to regulatory T cells in HIV disease. Sci Transl Med. 2010;2(32):32ra36.

35. Cherayil BJ. Indoleamine 2,3-dioxygenase in intestinal immunity and inflammation. Inflamm Bowel Dis. 2009;15(9):1391-1396.
Clinical and Experimental Gastroenterology

\section{Publish your work in this journal}

Clinical and Experimental Gastroenterology is an international, peerreviewed, open access, online journal publishing original research, reports, editorials, reviews and commentaries on all aspects of gastroenterology in the clinic and laboratory. This journal is included on PubMed. The manuscript management system is completely online

\section{Dovepress}

and includes a very quick and fair peer-review system, which is all easy to use. Visit http://www.dovepress.com/testimonials.php to read real quotes from published authors. 